\title{
EXAFS investigation on U(VI) immobilization in hardened cement paste: influence of experimental conditions on speciation
}

\author{
By N. Macé ${ }^{1, *}$, E. Wieland ${ }^{1}$, R. Dähn ${ }^{1}$, J. Tits ${ }^{1}$ and A. C. Scheinost ${ }^{2,3}$ \\ ${ }^{1}$ Paul Scherrer Institut, Laboratory for Waste Management, CH-5232 Villigen PSI, Switzerland \\ ${ }^{2}$ Helmholtz-Center Dresden-Rossendorf, Institute of Resource Ecology, 01314 Dresden, Germany \\ ${ }^{3}$ Rossendorf Beamline (ROBL), ESRF, 38043 Grenoble, France
}

(Received March 29, 2012; accepted in revised form September 4, 2012)

(Published online April 29, 2013)

\section{U(VI) / Speciation / Cement / (Micro-)EXAFS}

\begin{abstract}
Summary. Extended X-ray absorption fine structure (EXAFS) spectroscopy has been used to investigate the coordination environment of $\mathrm{U}(\mathrm{VI})$ in cementitious materials. The EXAFS measurements were carried out on U(VI)-doped samples prepared under varying conditions, such as samples from sorption, hydration and diffusion experiments, and using different cementitious materials, such as crushed hardened cement paste (HCP) and calcium silicate hydrates (C-S-H). The samples had U(VI) loadings ranging from $1700 \mu \mathrm{g} / \mathrm{g}$ to $45000 \mu \mathrm{g} / \mathrm{g}$. Applying principal component analysis (PCA) on 13 EXAFS spectra (each spectra corresponding to a minimum of five different scans) of the low loading samples, one single species is obtained indicating a similar U(VI) coordination environment for both HCP and C-S-H samples. This result confirms that $\mathrm{C}-\mathrm{S}-\mathrm{H}$ phases control the uptake of $\mathrm{U}(\mathrm{VI})$ in the complex cement matrix. The coordination environment of this species is similar to a $\mathrm{U}(\mathrm{VI})$ surface complex or to $\mathrm{U}(\mathrm{VI})$ in uranyl silicate minerals (two axial $\mathrm{O}$ atoms at $1.82 \pm 0.02 \AA$; four equatorial $\mathrm{O}$ atoms at $2.25 \pm 0.01 \AA$; one $\mathrm{Si}$ atom at $3.10 \pm 0.03 \AA$ ). At high $\mathrm{U}(\mathrm{VI})$ loading, PCA revealed a second $\mathrm{U}(\mathrm{VI})$ species, with a coordination environment similar to that of $\mathrm{U}(\mathrm{VI})$ in calcium uranate (two axial $\mathrm{O}$ atoms at $1.94 \pm 0.04 \AA$; five equatorial $\mathrm{O}$ atoms at $2.26 \pm 0.01 \AA$; four $\mathrm{Ca}$ atoms at $3.69 \pm 0.05 \AA$ and five $\mathrm{U}$ atoms at $3.85 \pm 0.04 \AA$ ).

This study shows that, at low U(VI) loading, U(VI) is bound to $\mathrm{C}-\mathrm{S}-\mathrm{H}$ phases in HCP while at high U(VI) loading, the immobilization of $\mathrm{U}(\mathrm{VI})$ in cementitious materials is mainly controlled by the precipitation of a calcium uranatetype phase.
\end{abstract}

\section{Introduction}

Cementitious materials are an important component of multi-barrier systems developed worldwide for the safe disposal of low- and intermediate-level radioactive waste (L/ILW). Uranium is an important contaminant in some of these waste forms. The immobilization of U(VI) by cementitious materials is still poorly understood at the atomic level while, it is well known that $\mathrm{U}(\mathrm{VI})$ is strongly retarded by hardened cement paste $(\mathrm{HCP})$ and its main constituent $(\sim 50$

\footnotetext{
*Author for correspondence (E-mail: nathalie.mace@cea.fr).
}

weight (wt) \%) calcium silicate hydrate phases (C-S-H) [e.g. 1-3]. Furthermore, extended X-ray absorption fine structure (EXAFS) spectroscopy on U(VI)-doped C-S-H samples suggested a chemical environment of U(VI) similar to that of $\mathrm{U}(\mathrm{VI})$ in the uranyl silicate mineral uranophane [4].

EXAFS studies on U(VI)-loaded untreated and hydrothermally treated HCP samples further revealed preservation of the $\mathrm{UO}_{2}{ }^{2+}$ moiety in all samples, indicating that the + VI redox state was stable $[5,6]$. Samples with U(VI)sorbed onto hydrothermally altered concrete also suggested cluster formation or surface precipitation as indicated by the presence of $\mathrm{U}-\mathrm{U}$ backscattering contributions in the EXAFS spectra [6]. The chemical nature of the U(VI) species immobilized in HCP has not yet been identified.

The present study aims at improving our current knowledge of $\mathrm{U}(\mathrm{VI})$ immobilization in cementitious environments. This information is further considered to improve long-term predictions of the retention of $\mathrm{U}(\mathrm{VI})$ in a cementbased repository. EXAFS spectroscopy has been used to determine the chemical environment of $\mathrm{U}(\mathrm{VI})$ taken up by hydrating cement, fully hydrated HCP samples and C-S-H phases at low and high U(VI) loadings. The C-S-H phases have been chosen because they are the major constituent of $\mathrm{HCP}$, and because previous studies suggested a high affinity of U(VI) for C-S-H [1, 3, 8]. Since the latter studies provided some evidence that loading levels have an influence on $\mathrm{U}$ speciation in C-S-H phases and HCP $[1,3,4,7,8]$, we investigated the influence of loading more systematically.

\section{Materials and methods}

\subsection{U(VI) reference compounds}

Ca-uranate $\left(\mathrm{CaUO}_{4} \cdot \mathrm{H}_{2} \mathrm{O}\right)$ and uranophane $\left(\mathrm{Ca}\left(\mathrm{UO}_{2}\right)_{2}\right.$ $\left.\left(\mathrm{SiO}_{3} \mathrm{OH}\right)_{2} \cdot 5 \mathrm{H}_{2} \mathrm{O}\right)$ were synthesized by Moroni and Glasser [9] and their characterization is described elsewhere $[9,10]$. The $\mathrm{CaUO}_{4} \cdot \mathrm{H}_{2} \mathrm{O}$ sample was reported to be a hydrated calcium uranate [9] and initially named "phase X". Briefly, synthesis was done by mixing calcium nitrate and uranyl nitrate solution with a $\mathrm{NaOH}$ solution under $\mathrm{N}_{2}$ atmosphere. The precipitate was stirred for $1 \mathrm{~h}$ and then stored at $85^{\circ} \mathrm{C}$ for 1 week. The composition of the phase, determined 
by energy dispersive X-ray spectroscopy (EDX) and thermoanalysis (DTA/TGA) [9], was given to be $\mathrm{CaUO}_{4} \cdot \mathrm{H}_{2} \mathrm{O}$. Soddyite $\left(\left(\mathrm{UO}_{2}\right)_{2} \mathrm{SiO}_{4} \cdot 2 \mathrm{H}_{2} \mathrm{O}\right)$ was synthesized using a procedure published elsewhere [11]. Prior to use, all reference materials were characterized by powder X-ray diffraction (XRD) and scanning electron microscopy coupled to energy dispersive microanalysis (SEM/EDX).

The XRD measurements were performed using a Philips analytical X-ray diffractometer with a $\mathrm{Cu} K_{\alpha}$ source. The SEM analysis was carried out using a Zeiss DSM962 microscope, operated at an accelerating voltage of $30 \mathrm{kV}$. The microscope is equipped with a $\mathrm{Si}(\mathrm{Li})$-detector for $\mathrm{EDX}$. The spot size area was approximately $1 \times 1 \mu \mathrm{m}^{2}$, with a penetration depth of $\sim 6 \mu \mathrm{m}$ at the incident beam energy. The microscope is further equipped with a scintillatorphotomultiplier system for backscattered electron (BSE) imaging and mineral phase specification, which is based upon differences in the gray scale.

\subsection{Preparation of U(VI)-doped samples}

All sample preparations involving alkaline solutions and solids were performed in a glove-box under a $\mathrm{N}_{2}$ atmosphere $\left(\mathrm{O}_{2}, \mathrm{CO}_{2}<2 \mathrm{ppm}\right)$ in order to prevent $\mathrm{CO}_{2}$ contamination. Solutions were prepared using deionised and decarbonated water generated by a Milli- $Q$ Gradient A10 System (Milli- pore, Bedford, USA) followed by degassing with $\mathrm{N}_{2}$ for at least $2 \mathrm{~h}$. HCP samples were prepared using a sulfate resistant Portland cement (CEM I 52.5 N HTS (Haute Teneur en Silice), Lafarge, France) with a high silica content. An artificial cement pore water solution (ACW) was used with a chemical composition in equilibrium with HCP and simulating the initial pore water conditions of hydrated cement $(\mathrm{pH}=13.3)[12]$.

C-S-H phases with target $\mathrm{CaO} / \mathrm{SiO}_{2}(\mathrm{C} / \mathrm{S})$ molar ratios of $0.7,1.07$ and 1.8 were synthesized in Milli-Q water (alkali-free solution) or ACW (alkali-rich solution), respectively. Details of synthesis of these C-S-H phases leading to effective $\mathrm{C} / \mathrm{S}$ ratios of $0.75,1.07$ and 1.65 were reported elsewhere [13].

For this study, a large number of HCP samples with different uranium loadings were prepared following various preparation procedures. U(VI)-doped samples were obtained from sorption experiments (U(VI)-doped sorption samples), from cement hydration experiments (U(VI)-doped hydration samples) and from an in-diffusion experiment (U(VI)-doped diffusion sample). Furthermore, U(VI)-doped C-S-H samples were obtained from sorption experiments. The complete list of U(VI)-doped cementitious samples prepared at low U(VI) loading (U(IV) concentrations from 1700 to $3700 \mu \mathrm{g} / \mathrm{g}$ ) and high U(VI) loading (U(IV) concentrations from 13600 to $45000 \mu \mathrm{g} / \mathrm{g}$ ) is given in Tables 1

Table 1. Chemical conditions of the U(VI)-doped cementitious samples at low loading used for bulk-EXAFS and $\mu$-EXAFS measurements.

\begin{tabular}{|c|c|c|c|c|c|c|c|}
\hline $\begin{array}{l}\text { Measurement } \\
\text { type }\end{array}$ & $\begin{array}{l}\text { Experiment } \\
\text { type }\end{array}$ & Sample & $\begin{array}{l}\text { Solid/liquid } \\
\text { (g/L) }\end{array}$ & $\begin{array}{l}{[\mathrm{U}(\mathrm{VI})]_{0}} \\
(\mathrm{M})\end{array}$ & $\begin{array}{l}{[\mathrm{U}(\mathrm{VI})]_{\text {solid }}} \\
\quad(\mu \mathrm{g} / \mathrm{g})\end{array}$ & $\begin{array}{l}\text { Equilibration } \\
\text { (d) }\end{array}$ & $\begin{array}{l}\text { Spectrum } \\
\text { label }\end{array}$ \\
\hline \multirow{12}{*}{ Bulk-EXAFS } & \multirow{9}{*}{ Sorption } & C-S-H/0.7_ $\mathrm{H}_{2} \mathrm{O}$ & 75 & $5.4 \times 10^{-4}$ & 1700 & 309 & LL_1 \\
\hline & & C-S-H/0.7_ACW & 75 & $5.4 \times 10^{-4}$ & 1700 & 309 & LL_2 \\
\hline & & C-S-H/1.07_H $\mathrm{H}_{2} \mathrm{O}$ & 70 & $5.5 \times 10^{-4}$ & 1900 & 35 & LL_3 \\
\hline & & \multirow{3}{*}{ C-S-H/1.07_ACW } & \multirow{3}{*}{70} & \multirow{3}{*}{$5.5 \times 10^{-4}$} & \multirow{3}{*}{1900} & 309 & $\mathrm{LL}_{-} 4$ \\
\hline & & & & & & 35 & LL_5 \\
\hline & & & & & & 309 & LL_6 \\
\hline & & C-S-H/1.8_ $\mathrm{H}_{2} \mathrm{O}$ & 60 & $5.4 \times 10^{-4}$ & 2100 & 309 & $\mathrm{LL}_{-} 7$ \\
\hline & & HCP_ACW & 25 & $3.2 \times 10^{-4}$ & 3000 & 30 & LL_8 \\
\hline & & HCP_ACW & \multirow{4}{*}{13000} & $3.9 \times 10^{-4}$ & 3700 & 120 & LL_9 \\
\hline & \multirow[t]{3}{*}{ Hydration } & \multirow[t]{3}{*}{ CEM_H ${ }_{2} \mathrm{O}$} & & \multirow[t]{3}{*}{$1.4 \times 10^{-1}$} & \multirow[t]{3}{*}{2600} & 1 & $\mathrm{LL}_{-} 10$ \\
\hline & & & & & & 28 & LL_11 \\
\hline & & & & & & 290 & LL_12 \\
\hline$\mu$-EXAFS & Diffusion & HCP_ACW & - & - & - & 270 & LL_13 (1 spot) \\
\hline
\end{tabular}

Table 2. Chemical conditions of the U(VI)-doped cementitious samples at high loading used for bulk-EXAFS and $\mu$-EXAFS measurements.

\begin{tabular}{|c|c|c|c|c|c|c|c|}
\hline $\begin{array}{l}\text { Measurement } \\
\text { type }\end{array}$ & $\begin{array}{l}\text { Experiment } \\
\text { type }\end{array}$ & Sample & $\begin{array}{l}\text { Solid/liquid } \\
\text { (g/L) }\end{array}$ & $\begin{array}{l}{[\mathrm{U}(\mathrm{VI})]_{0}} \\
(\mathrm{M})\end{array}$ & $\begin{array}{l}{[\mathrm{U}(\mathrm{VI})]_{\text {solid }}} \\
\quad(\mu \mathrm{g} / \mathrm{g})\end{array}$ & $\begin{array}{l}\text { Equilibration } \\
\text { (d) }\end{array}$ & $\begin{array}{l}\text { Spectrum } \\
\text { label }\end{array}$ \\
\hline Bulk-EXAFS & Sorption & $\begin{array}{l}\text { C-S-H/0.7_H } \mathrm{H}_{2} \mathrm{O} \\
\text { C-S-H/0.7_ACW } \\
\text { C-S-H/1.07_H } \mathrm{H}_{2} \mathrm{O} \\
\text { C-S-H/1.8_H } \mathrm{H}_{2} \mathrm{O} \\
\mathrm{HCP} \_\mathrm{ACW} \\
\text { CEM_H } \mathrm{H}_{2} \mathrm{O}\end{array}$ & $\begin{array}{c}76 \\
76 \\
70 \\
60 \\
25 \\
13000\end{array}$ & $\begin{array}{l}4.4 \times 10^{-3} \\
4.4 \times 10^{-3} \\
4.5 \times 10^{-3} \\
4.4 \times 10^{-3} \\
4.7 \times 10^{-3} \\
\quad 1.3\end{array}$ & $\begin{array}{l}13600 \\
13600 \\
15200 \\
17100 \\
45000 \\
25500\end{array}$ & $\begin{array}{r}309 \\
309 \\
309 \\
309 \\
120 \\
28 \\
290\end{array}$ & $\begin{array}{l}\text { HL_1 } \\
\text { HL_2 } \\
\text { HL_3 } \\
\text { HL_4 } \\
\text { HL_5 } \\
\text { HL_6 } \\
\text { HL_7 }\end{array}$ \\
\hline$\mu$-EXAFS & Hydration & CEM_H ${ }_{2} \mathrm{O}$ & 13000 & 1.3 & 25500 & $\begin{array}{r}1 \\
28 \\
365 \\
450\end{array}$ & $\begin{array}{c}\text { HL_8 (4 spots) } \\
\text { HL_9 (3 spots) } \\
\text { HL_10 (8 spots) } \\
\text { HL_11 (3 spots) }\end{array}$ \\
\hline
\end{tabular}


and 2. Details of sample preparation are given in the following sections.

\subsubsection{U(VI)-doped sorption samples at low loadings (LL_1-LL_9)}

For the preparation of the U(VI)-doped C-S-H and HCP samples, the initial U(VI) concentration was chosen in the concentration range suitable for EXAFS investigations and according to the linear sorption isotherm published elsewhere $[3,7]$. The final U(VI) loadings ranged between $1700 \mu \mathrm{g} / \mathrm{g}$ and $3700 \mu \mathrm{g} / \mathrm{g}$, which correspond to equilibrium solution concentrations well below the solubility limit of any U(VI) solid phase. $\mathrm{C}-\mathrm{S}-\mathrm{H}$ phases $(\mathrm{C} / \mathrm{S}=0.7-1.8)$ and crushed hydrated HCP samples were mixed with either alkali-free solution $\left(\mathrm{H}_{2} \mathrm{O}\right)$ or $\mathrm{ACW}$. To these suspensions, aliquots of U(VI) were added to achieve the U(VI) loadings listed in Table 1. The suspensions were equilibrated over time periods ranging from 30 to 309 days.

After equilibration for appropriate periods of time, solid and liquid phases were separated by centrifugation. The concentrations of $\mathrm{U}, \mathrm{Ca}, \mathrm{Si}, \mathrm{Na}, \mathrm{K}$ and $\mathrm{Al}$ in the supernatant solutions were determined using inductively coupled plasma optical emission spectroscopy (ICP-OES). The solids were separated, dried under a $\mathrm{N}_{2}$ atmosphere for about $8 \mathrm{~h}$ at room temperature and stored until further use for the bulk-EXAFS measurements.

\subsubsection{U(VI)-doped hydration samples at low loading (LL_10-LL_12)}

The U(VI)-doped hydration samples were prepared by mixing unhydrated HTS cement with a U(VI) solution at a water/cement $(\mathrm{w} / \mathrm{c})$ ratio of 0.4 following a procedure described elsewhere [14]. The U(VI) solution was prepared by dissolving $\mathrm{UO}_{2}\left(\mathrm{NO}_{3}\right)_{2} \cdot 6 \mathrm{H}_{2} \mathrm{O}$ (Sigma-Aldrich, Switzerland) in $\mathrm{HNO}_{3}\left(10^{-4} \mathrm{M}\right)$ to obtain a stock solution with a concentration of $0.81 \mathrm{M}(\mathrm{pH}=3.5-4)$. The U(VI)-doped pastes were cast in Plexiglas moulds (height: $1 \mathrm{~cm}$; diameter: $0.8 \mathrm{~cm}$ ), which were sealed with a polyethylene lid. The samples were stored at room temperature and $100 \%$ relative humidity in a closed container, which was placed in a glovebox under a $\mathrm{N}_{2}$ atmosphere. After ageing for 1, 28 and 290 days, the samples were extruded from the cast, immersed in acetone for $12 \mathrm{~h}$ to stop the hydration process, and dried over night at $60{ }^{\circ} \mathrm{C}$ to evaporate intruded acetone. XRD measurements were performed in order to check that the drying procedure had no major effects onto the cement composition. The intact specimens were crushed and sieved to collect the size fraction $<63 \mu \mathrm{m}$ for further use in the EXAFS measurements. The final U(VI) loading of the cement pastes was $\sim 2600 \mu \mathrm{g} / \mathrm{g}$.

\subsubsection{U(VI)-doped diffusion sample at low loading (LL_13)}

The LL_13 sample was a thin section prepared from the cross section of a $1 \mathrm{~cm}$ thick HCP disk in contact with ACW solution and subjected to U(VI) in-diffusion. Details of the sample preparation and $\mu$-EXAFS measurements were reported elsewhere [7].

\subsubsection{U(VI)-doped sorption samples at high loadings (HL_1-HL_5)}

These samples were prepared following a procedure similar to that used for the samples LL_1 to LL_9, except that the final U(VI) loadings were much higher (range $13600-45000 \mu \mathrm{g} / \mathrm{g})$. After equilibration between 120 and $309 \mathrm{~d}$, the U(VI) doped materials were sampled for bulkEXAFS measurements as described for LL_1-LL_9.

\subsubsection{U(VI)-doped hydration samples at high loading (HL_6-HL_11)}

These samples were prepared following a procedure similar to that used for the samples LL_10 to LL_12, except that the final U(VI) loading was much higher $(\sim 25500 \mu \mathrm{g} / \mathrm{g})$. After ageing between 1 and $450 \mathrm{~d}$, the U(VI)-doped materials were prepared for the spectroscopic measurements. The HL_6-HL_7 samples were prepared by crushing the intact HCP specimens for bulk-EXAFS studies while the samples HL_8-HL_11 were thin sections for $\mu$-EXAFS analyses.

\subsection{Synchrotron-based spectroscopic investigations}

\subsubsection{Bulk-EXAFS sample preparation}

The U(VI)-doped C-S-H and HCP sorption samples, as well as the U(VI)-doped hydration samples, were cast in Plexiglas holders, sealed with two layers of Kapton ${ }^{\circledR}$ tape and in addition with thermo-sealed polyethylene bags.

The U(VI) reference samples were prepared by diluting $\sim 15 \mathrm{mg}$ of the U(VI) minerals (uranophane, soddyite, and $\mathrm{CaUO}_{4} \cdot \mathrm{H}_{2} \mathrm{O}$ ) with $250 \mathrm{mg}$ boron nitride ( $\mathrm{BN}, 98 \%$ purity, Sigma-Aldrich, Switzerland). The reference samples were also filled into Plexiglas holders and double-sealed.

Two samples, the LL_9 and the soddyite samples, were also sealed in special sample holders for cryogenic EXAFS measurements $(15 \mathrm{~K})$.

\subsection{2 $\mu$-EXAFS sample preparation}

Several hydration samples and the diffusion sample were analyzed using micro-X-ray fluorescence $(\mu$-XRF) and micro-X-ray absorption spectroscopy ( $\mu$-EXAFS). For each of these samples, a thin section was prepared from the cross section by polishing the cementitious material after pressure impregnation with epoxy resin (Th. Beckmann, Soil morphology, Schwülper-Lagersbüttel, Germany, pers. comm.).

\subsubsection{Bulk- and $\mu$-EXAFS data collection and reduction}

Bulk-EXAFS spectra at the $U L_{\text {III }}$ edge $(17166 \mathrm{eV})$ were collected at room temperature at BM 20 (ROBL) at the European Synchrotron Radiation Facility (ESRF) in Grenoble, France [15]. The beamline is equipped with a water-cooled Si(111) double crystal monochromator between Pt-coated mirrors for beam collimation and rejection of higher order harmonics. The monochromator position was calibrated by assigning the first inflection point of the $K$-absorption edge of a Y foil to $17038 \mathrm{eV}$. Several scans were averaged to improve the signal-to-noise ratio (reference samples: 3 scans; U(VI) sorbed samples: up to 9 scans). The spectra of the reference samples were recorded in transmission mode while 
the spectra of the U(VI)-doped samples were recorded in fluorescence mode using a 13-element Ge solid-state detector (Canberra) with digital signal treatment (XIA).

For two samples, the spectra were recorded at $15 \mathrm{~K}$ in order to check the possibility of improving the signal-tonoise ratio, which would increase the $k$-space available for the determination of structural parameters.

The $\mu$-XRF/EXAFS measurements were performed at BL 2-3 at the Stanford Synchrotron Radiation Lightsource (SSRL) of the SLAC National Accelerator Laboratory (Menlo Park, CA, USA). The beamline is equipped with a Si(111) double-crystal monochromator and a KirkpatrickBaez (KB) mirror focusing system. The monochromator position was calibrated by assigning the first inflection point of the K-absorption edge of the Y foil to $17038 \mathrm{eV}$. The $\mathrm{X}$ ray beam was focused down to about $2 \times 2 \mu \mathrm{m}^{2}$ spot size. Fluorescence radiation was detected using a single channel VORTEX Si detector. The elemental distribution maps (U, $\mathrm{Ca}, \mathrm{K}$ and $\mathrm{Fe}$ ) were recorded using a $2 \mu \mathrm{m}^{2}$-pixel-size and a dwell time per point of $250 \mathrm{~ms}$.

A total of 17 EXAFS spectra were recorded on the selected U(VI) rich spot of the LL_13 sample to achieve the requested signal-to-noise ratio. In case of the HL samples spectra were recorded on different spots and merged if the spectra were found to be identical. For example, the spectrum of the HL_8 sample was merged using 5 identical spectra recorded on 4 different U(VI) rich spots. The other HL spectra were obtained as follows: HL_9 from 45 identical spectra recorded on 3 different U(VI) rich spots; HL_10 from 10 spectra recorded on each of 8 different $\mathrm{U}(\mathrm{VI})$ rich spots and as the spectra were not identical, each spot was considered individually in the data treatment; HL_11 from 5 identical spectra recorded on 3 different U(VI) rich spots.

Bulk-EXAFS and $\mu$-EXFAS data reduction and analysis were performed using the SIXPACK/IFEFFIT software following standard procedures [18-22]. SIXPACK was used for dead-time correction and for averaging the spectra [18]. Reduction and modeling of the EXAFS data were performed using the ATHENA/ARTEMIS software package [19,20]. After background subtraction, the energy was converted to photoelectron wave vector units $\left(\AA^{-1}\right)$ by assigning the ionization energy of the $U L_{\mathrm{III}}$-edge to the first inflection point of the absorption edge. Radial structure functions (RSFs) were obtained by Fourier transforming $k^{3}$-weighted $\chi(k)$ functions between 2.0 and $16.0 \AA^{-1}$ for the reference compounds and between 2.0 and $11.0 \AA^{-1}$ for the U(VI)doped samples using a Kaiser-Bessel window function with a parameter of 4. A multi shell approach was employed for data fitting. Theoretical single and multiple scattering paths (SS and MS paths, respectively) were calculated using FEFF8.20 $[21,22]$ and the $\alpha$-uranophane or soddyite structures as model compounds $[23,24]$. The relevant SS paths included U-O (axial), U-O (equatorial), U-Si, U-Ca and $\mathrm{U}-\mathrm{U}$ for the $\mathrm{U}(\mathrm{VI})$ reference compounds and $\mathrm{U}-\mathrm{O}$ (axial), $\mathrm{U}-\mathrm{O}$ (equatorial), $\mathrm{U}-\mathrm{Si}$ for the $\mathrm{U}(\mathrm{VI})$-doped cement and C-S-H samples. Three MS backscattering paths $\left(\mathrm{MS}_{1}, \mathrm{MS}_{2}\right.$ and $\mathrm{MS}_{3}$ ) were considered for all fits as described elsewhere [25], except for $\mathrm{CaUO}_{4} \cdot \mathrm{H}_{2} \mathrm{O}$. The $\mathrm{MS}_{1}, \mathrm{MS}_{2}$ and $\mathrm{MS}_{3}$ paths account for $\mathrm{U}-\mathrm{O}_{1}-\mathrm{U}-\mathrm{O}_{2}$ (4-legged axial across both axial $\mathrm{O}$ atoms), $\mathrm{U}-\mathrm{O}_{1}-\mathrm{U}-\mathrm{O}_{1}$ (4-legged across only one of the axial $\mathrm{O}$ atoms) and $\mathrm{U}-\mathrm{O}_{1}-\mathrm{O}_{2}-\mathrm{U}$ (3-legged axial) paths, respectively. The amplitude reduction factor, $S_{0}^{2}$, was held constant using a value of 1.0 for all fits. The total number of variables was calculated to range between 9 and 16 depending on the $R$ range and the number of shells over which the fit was made [26]. Some variables were held constant in order to reduce the number of fitted parameters. For example, the coordination number $(N)$ of the first shell was held constant, simulating the axial oxygen atoms of the uranyl structure, as the X-ray absorption near edge structure (XANES) part of the spectra did not indicate any change in the redox state. In case of the $\mathrm{U}(\mathrm{VI})$ reference compounds, the coordination numbers of all neighboring atoms were held constant in accordance with the XRD data published in the literature [10,23, 24, 27]. For each fit, the threshold energy $\left(\Delta E_{0}\right)$ was linked for all shells and was allowed to vary as a global parameter. Floating parameters of the first shell were the Debye-Waller (DW) factor $\left(\sigma^{2}\right)$ and the bond distance $(R)$. The parameters of the MS paths were defined as follows: delta_R( $\left(\mathrm{MS}_{1}\right)=\operatorname{delta} \mathrm{R}\left(\mathrm{MS}_{2}\right)=$ delta_R $\left(\mathrm{MS}_{3}\right)=2 \times$ delta_R$\left(\mathrm{U}-\mathrm{O}_{\text {axial }}\right)$, with delta_R as the difference between the theoretical distance of the considered shell $\left(R_{\text {eff }}\right)$ and the fitted bond length, R. The DW factors were set as follows: $\sigma\left(\mathrm{MS}_{1}\right)=\sigma\left(\mathrm{MS}_{2}\right)=\sigma\left(\mathrm{MS}_{3}\right)=2 \times$ $\sigma\left(\mathrm{U}-\mathrm{O}_{\text {axial }}\right)$ [25]. The latter assumption implies that the path length and DW factor of each MS path is related to the SS axial oxygen path. The fitting approach was tested on several reference compounds (soddyite, becquerelite, $\alpha$ uranophane, $\mathrm{CaUO}_{3.8}$ and $\mathrm{K}$-boltwoodite) based on the comparison of fitted data with the crystallographic distances reported in the literature [10, 23, 24, 27-29].

Analyses of the bulk- and $\mu$-EXAFS spectra from all $\mathrm{U}(\mathrm{VI})$-doped samples were based on the assumption that several U(VI) species contributed to the overall EXAFS signal. Therefore, principal component analysis (PCA) was applied in combination with iterative target transformation (ITT), allowing a series of related EXAFS spectra to be decomposed into its principal components (PC) without a priori knowledge about the system studied [16]. Two PCA programs were applied in this study: the Labview software package of beamline 10.3.2/ALS [17] and the PCA program implemented in SIXPACK [18]. Data analyses were performed in the $k$ range from 2 to $6 \AA^{-1}$, which contained the main spectral features that allowed the two principal coordination environments of U(VI), that is the uranyl-silicate-like and calcium-uranate-like arrangements, to be distinguished from each other. The outcomes of both programs were found to agree very well. The indicator value (IND) was the criterion applied to determine the minimum number of independent components allowing the set of experimental spectra to be reproduced [16].

\section{Results and discussion}

\subsection{U(VI) reference compounds}

Several U(VI) minerals were selected as reference materials: Soddyite represents the local structure of uranyl in a Cafree uranyl-silicate-like chemical environment, which might form in U(VI)-doped C-S-H systems. Uranophane as Cacontaining uranyl silicate mineral might represent the chemical environment of U(VI) taken up by cementitious materi- 

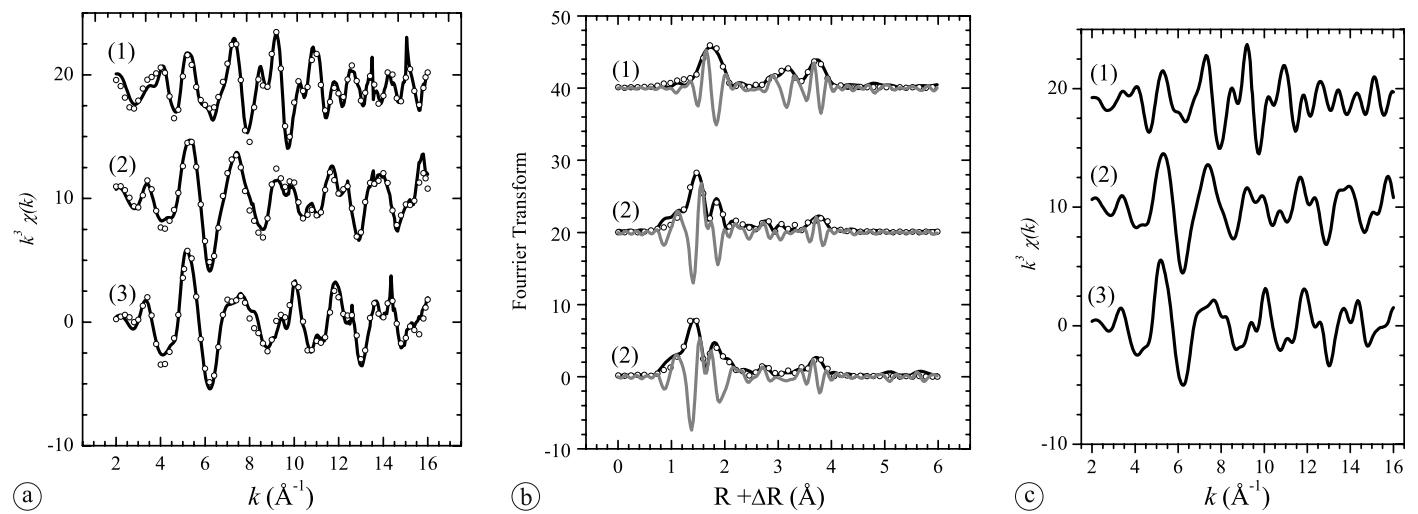

Fig. 1. Experimental spectra of the U(VI) reference compounds (1) Ca-uranate, (2) uranophane, (3) soddyite determined at room temperature. (a) $k^{3}$-weighted, normalized and background subtracted (solid lines) and theoretical (dots) EXAFS spectra, (b) experimental (solid lines) and theoretical Fourier transforms (dots: modulus; broken line: imaginary part) for the $k$ range between 2 and $16 \AA^{-1}$ (not corrected for phase shift); (c) $k^{3}$-weighted EXAFS function of the Fourier-backtransform spectra in the $R+\Delta R$ range $=0.8-6 \AA$.

Table 3. Structural parameters for the U(VI) reference compounds $k$ range $=2-16 \AA^{-1}$.

\begin{tabular}{|c|c|c|c|c|c|c|c|c|}
\hline Sample & Shell & $N$ & $\begin{array}{c}R \\
(\AA)\end{array}$ & $\begin{array}{c}\sigma^{2} \\
\left(\AA^{2}\right)\end{array}$ & $\begin{array}{l}\Delta E_{0} \\
(\mathrm{eV})\end{array}$ & $\begin{array}{c}R- \\
\text { factor }(\%)\end{array}$ & $\begin{array}{c}R(\AA) \times N \\
\text { from XRD data }\end{array}$ & Reference \\
\hline $\begin{array}{l}\text { Ca-uranate } \\
\text { No MS paths }\end{array}$ & $\begin{array}{l}\mathrm{O}_{\mathrm{ax}} \\
\mathrm{O}_{\mathrm{eq}} \\
\mathrm{Ca} \\
\mathrm{U}_{1}\end{array}$ & $\begin{array}{c}2.0\left(^{a}\right) \\
5.5(5) \\
4(1) \\
3(1)\end{array}$ & $\begin{array}{l}1.93(4) \\
2.25(1) \\
3.64(4) \\
3.87(4)\end{array}$ & $\begin{array}{l}0.005(1) \\
0.007(1) \\
0.008(2) \\
0.005(1)\end{array}$ & $5(1)$ & 0.2 & $\begin{array}{l}1.95(4) \times 2 \\
2.30(1) \times 6 \\
3.69(4) \times 6 \\
3.88(4) \times 6\end{array}$ & $\begin{array}{l}{[10]} \\
{[27]}\end{array}$ \\
\hline Uranophane & $\begin{array}{l}\mathrm{O}_{\mathrm{ax}} \\
\mathrm{O}_{\text {eq1 }} \\
\mathrm{O}_{\text {eq2 }} \\
\mathrm{Si}_{1} \\
\mathrm{Si}_{2} \\
\mathrm{Si}_{3} \\
\mathrm{U}_{1} \\
\mathrm{Ca}\end{array}$ & $\begin{array}{l}2.0\left(^{a}\right) \\
3.0\left({ }^{a}\right) \\
2.0\left(^{a}\right) \\
1.0\left(^{a}\right) \\
1.0\left(^{a}\right) \\
2.0\left(^{a}\right) \\
2.0\left(^{a}\right) \\
1.0\left({ }^{a}\right)\end{array}$ & $\begin{array}{l}1.82(2) \\
2.27(1) \\
2.44(2) \\
3.16(2) \\
3.74(8) \\
3.93(4) \\
3.95(3) \\
4.00(13)\end{array}$ & $\begin{array}{l}0.002(1) \\
0.005(1) \\
0.008(4) \\
0.003(1) \\
0.007(7) \\
0.002(1) \\
0.007(3) \\
0.005\left({ }^{a}\right)\end{array}$ & $14(1)$ & 0.1 & $\begin{array}{l}1.805(15) \times 2 \\
2.277(20) \times 3 \\
2.450(10) \times 2 \\
3.144(10) \times 1 \\
3.632(10) \times 1 \\
3.767(14) \times 2 \\
3.924(10) \times 2 \\
4.070(10) \times 1\end{array}$ & [23] \\
\hline Soddyite & $\begin{array}{l}\mathrm{O}_{\mathrm{ax}} \\
\mathrm{O}_{\text {eq1 }} \\
\mathrm{O}_{\text {eq2 }} \\
\mathrm{Si}_{1} \\
\mathrm{Si}_{2} \\
\mathrm{U}_{1}\end{array}$ & $\begin{array}{l}2.0\left(^{a}\right) \\
2.0\left(^{a}\right) \\
3.0\left(^{a}\right) \\
1.0\left(^{a}\right) \\
2.0\left(^{a}\right) \\
2.0\left(^{a}\right)\end{array}$ & $\begin{array}{l}1.79(1) \\
2.31(2) \\
2.43(2) \\
3.16(2) \\
3.90(3) \\
3.87(1)\end{array}$ & $\begin{array}{l}0.002(1) \\
0.005(2) \\
0.009(3) \\
0.004(2) \\
0.007(4) \\
0.005(1)\end{array}$ & $14(1)$ & 0.1 & $\begin{array}{l}1.781(5) \times 2 \\
2.313(4) \times 2 \\
2.418(10) \times 3 \\
3.157(5) \times 1 \\
3.805(5) \times 2 \\
3.862(5) \times 2\end{array}$ & [24] \\
\hline
\end{tabular}

a: Parameters held constant.

als, if $\mathrm{Ca}$ was involved in U(VI) binding [4]. Ca-uranate was chosen as possible candidate for U(VI) solubility limiting phases in cementitious environments on the basis of earlier investigations [3].

The purity of synthesized soddyite was confirmed by XRD (PDF 00-035-0733) and SEM-EDX analyses (data not shown). Dry material was used for EXAFS measurements without prior treatment.

The SEM image of Ca-uranate showed an aggregatetype material (data not shown). The atomic proportions obtained from EDX patterns confirmed a $\mathrm{Ca}$ : $\mathrm{U}$ stoichiometry close to $1: 1$. Small amounts of $\mathrm{Na}$ impurities were detected. The XRD pattern matched the X-ray diffractogram of $\mathrm{CaUO}_{4} \cdot \mathrm{H}_{2} \mathrm{O}$ (PDF 00-085-0941).

The SEM image of uranophane showed an aggregatetype material consisting of small $(<2 \mu \mathrm{m})$ crystals (data not shown). Small amounts of $\mathrm{Na}$ and $\mathrm{K}$ were detected as impurities. The XRD data were found to match the X-ray diffractogram of $\mathrm{Ca}\left(\mathrm{UO}_{2}\right)_{2}\left(\mathrm{SiO}_{3} \mathrm{OH}\right)_{2} \cdot 5 \mathrm{H}_{2} \mathrm{O}(\mathrm{PDF} 00-078-1840)$.
EXAFS investigations on several U(VI) minerals, such as uranyl silicate and calcium uranyl compounds, have been reported to date [e.g. 30-33]. These studies show that structural parameters determined with EXAFS spectroscopy agree with those obtained from XRD measurements.

The EXAFS data of the selected U(VI) reference minerals are summarized in Fig. 1. Experimental EXAFS data and modeling were found to be in excellent agreement. Depending on the data quality, it was possible to resolve up to 8 different atomic shells (Table 3 ).

In general, the distances deduced from EXAFS were consistent with those obtained from XRD [10, 23, 24, 27]. Further, important aspects of the U(VI) coordination environment were confirmed, in particular the distance between $\mathrm{U}(\mathrm{VI})$ and the two axial oxygen atoms and the existence of a split equatorial oxygen shell.

Split equatorial oxygen shells with a short $\mathrm{U}-\mathrm{O}_{\mathrm{eq}}$ distance at $2.27 \AA$ and $2.31 \AA$ and a long one at $2.44 \AA$ and at $2.43 \AA$ were observed when fitting the uranophane and 
soddyite spectra, respectively. The distance between U(VI) and the two axial oxygen atoms varied between $1.79 \AA$ and $1.82 \AA$ for all investigated minerals. This agrees, within the given uncertainties, with distances reported in the literature and deduced from crystallographic data [23, 24].

In the case of $\mathrm{CaUO}_{4} \cdot \mathrm{H}_{2} \mathrm{O}$ the bond distance, $R_{\mathrm{U}-\mathrm{O}_{\mathrm{ax}}}$, was determined to be $1.94 \pm 0.04 \AA$, which is significantly longer than $R_{\mathrm{U}-\mathrm{O}_{\mathrm{ax}}}$ found in soddyite and uranophane $(1.79 \AA$ and $1.82 \AA$ ). Thus, the distances between U(VI) and the axial O atoms in uranyl silicates on the one hand, and Ca-uranate on the other hand, are significantly different and allow the corresponding coordination environments of U(VI) to be clearly identified.

Fitting of the spectrum of Ca-uranate further revealed that the oxygen shell around the central uranium atom can be adequately reproduced by two oxygen atoms in the axial position and $5.5 \pm 0.5$ oxygen atoms in the equatorial position. In contrast to the uranyl silicate minerals, however, the equatorial oxygen shell is uniform in $\mathrm{CaUO}_{4} \cdot \mathrm{H}_{2} \mathrm{O}$. All equatorial oxygen atoms are arranged at short distance around $\mathrm{U}(\mathrm{VI})$, which causes an elongation of the $\mathrm{U}-\mathrm{O}_{\mathrm{ax}}$ distance. Nevertheless, $\mathrm{CaUO}_{4} \cdot \mathrm{H}_{2} \mathrm{O}$ does not exhibit a structural arrangement of the $\mathrm{O}$ atoms typically observed in uranates $[27,34]$. In contrast to the uranates, the axial and equatorial oxygen shells can be distinguished in $\mathrm{CaUO}_{4} \cdot \mathrm{H}_{2} \mathrm{O}$, thus still reflecting an uranyl-type arrangement of the nearest oxygen shells. Therefore, presence of both axial and equatorial oxygen atoms is common to both uranyl-silicate-like and calcium-uranate-like coordination environments of U(VI). Nevertheless, the two coordination environments can be distinguished from each other based on differences in the distances of the axial and equatorial oxygen atoms.

\subsection{U(VI) EXAFS measurements at cryogenic temperature}

Fig. 2 shows that recording EXAFS spectra at cryogenic temperature improves the signal-to-noise ratio and resolution only of a well-crystallized compound with a high U(VI) content, such as soddyite. For an amorphous sample with low U(VI) loading (e.g. the LL_9 sample), however,

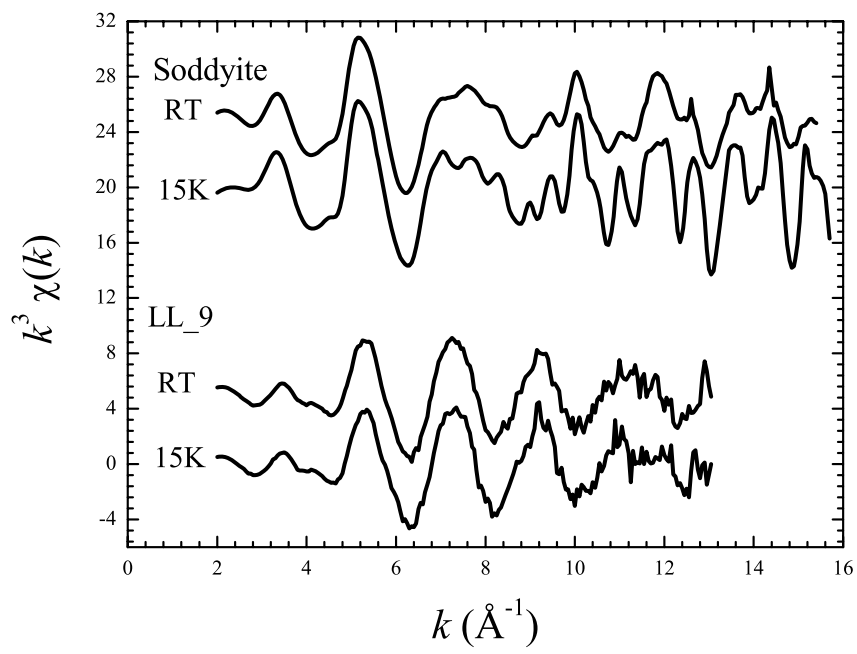

Fig. 2. Experimental spectra of soddyite and LL_9 sample recorded at room temperature (RT) and at cryogenic temperature $(15 \mathrm{~K})$.
EXAFS measurements at cryogenic temperature did not significantly improve the signal-to-noise ratio. This finding is in line with a high ratio of thermal vs. static disorder in wellcrystalline samples, while static disorder prevails in amorphous samples [e.g. 35]. As a consequence all measurements of the U(VI)-doped $\mathrm{C}-\mathrm{S}-\mathrm{H}$ and $\mathrm{HCP}$ samples were performed at room temperature.

\subsection{U(VI) speciation at low and high U(VI) loadings}

PCA was carried out, first using the set of bulk-EXAFS spectra shown in Fig. 3 (low U(VI) loadings, spectra of samples LL_1 to LL_13) and second, using the set of bulk- and

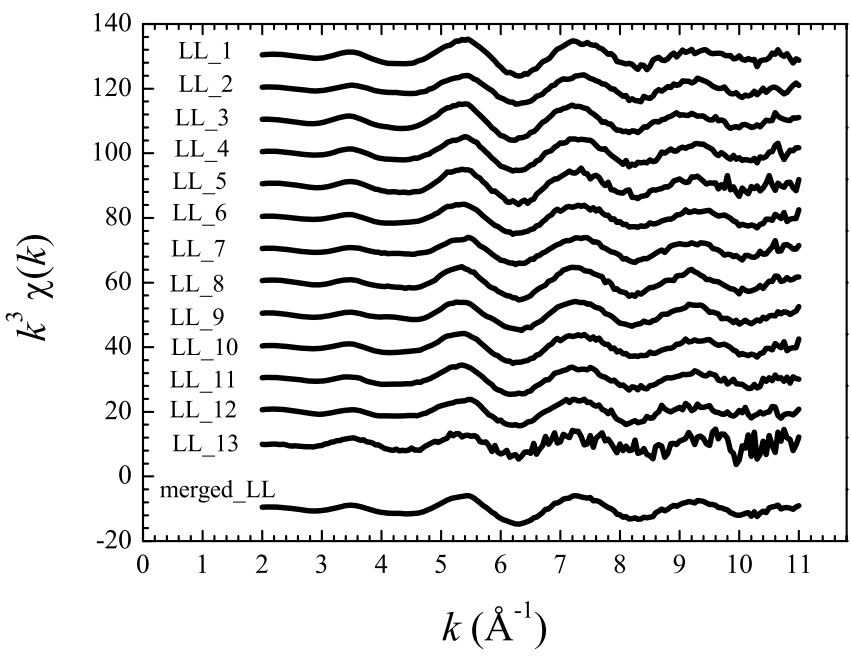

Fig. 3. Experimental $k^{3}$-weigthed, normalized and background-subtracted bulk-EXAFS and $\mu$-EXAFS spectra of the U(VI)-doped samples at low loading (LL_1-LL_13) and the corresponding merged spectrum (merged_LL). The $k$ range was taken from 2 to $11 \AA^{-1}$ for all samples.

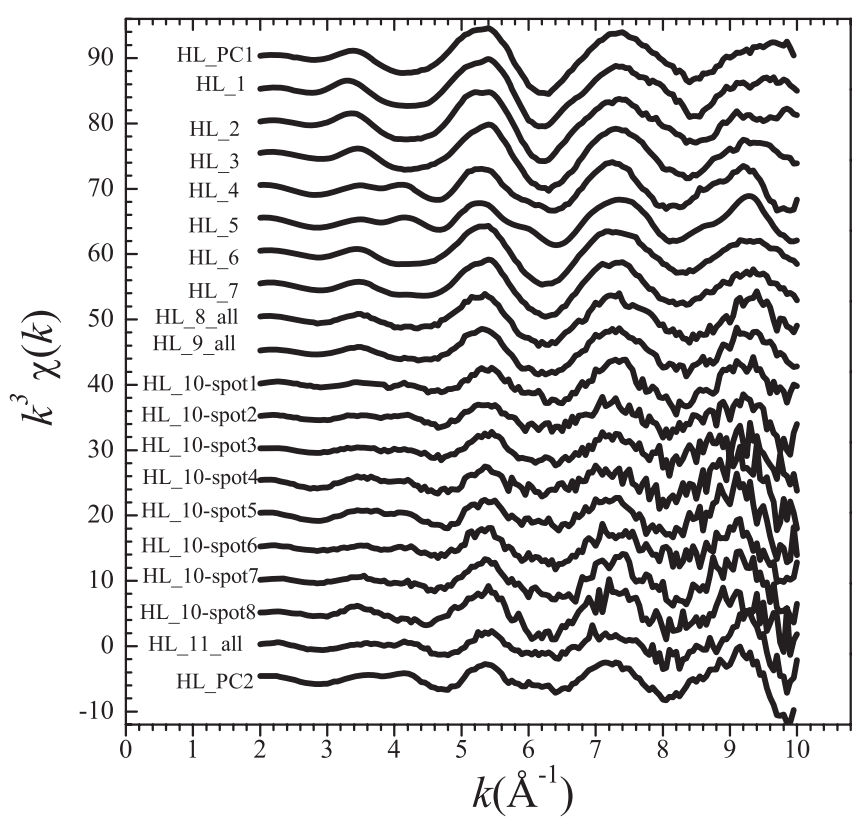

Fig. 4. Experimental $k^{3}$-weigthed, normalized and background-subtracted bulk-EXAFS and $\mu$-EXAFS spectra of the U(VI)-doped samples at high loading (HL_1-HL_11) and the corresponding principal component spectra (HL_PC1 (top) and HL_PC2 (bottom)). The $k$ range was taken from 2 to $10 \AA^{-1}$ for all samples. 
$\mu$-EXAFS spectra shown in Fig. 4 (high U(VI) loadings, spectra of sample HL_1-HL_11). This procedure was applied in order to determine independently for each series of data the principal component spectra that can reproduce all presupposed composed spectra.

The LL spectra were found to contain only one main component. This means that either U(VI) has the same coordination environment in all U(VI)-doped samples or the coordination environment of the different U(VI) species (and therefore the resulting spectra) are alike and could not be distinguished using PCA. This is in contrast with observations from time-resolved laser fluorescence spectroscopy (TRLFS) studies and wet chemistry studies of U(VI) sorbed on $\mathrm{C}-\mathrm{S}-\mathrm{H}$ phases which indicate the presence of at least two sorbed species with different coordination environments $[3,8]$. The relatively low signal-to-noise ratio of the EXAFS spectra and the limited $k$-range over which the spectra were collected, may be a reason why the second species could not be detected.

Furthermore, PCA indicated the presence of two different components (HL_PC1 and HL_PC2) in the HL spectra (Fig. 4).

\subsection{Coordination environment of U(VI) in cementitious systems at low $\mathrm{U}(\mathrm{VI})$ loading}

All spectra of the U(VI)-doped samples were merged as a consequence of the above observation that only one characteristic coordination environment of U(VI) is visible in the LL samples, thereby improving the signal-to-noise ratio of the resulting sum spectrum (Fig. 3, merged_LL). The presence of only one component has several implications. First, $\mathrm{U}(\mathrm{VI})$ has the same coordination environment in U(VI)doped C-S-H phases and U(VI)-doped crushed HCP samples, suggesting that $\mathrm{C}-\mathrm{S}-\mathrm{H}$ is the uptake-controlling cement phase for U(VI) in HCP. This finding corroborates conclusions presented in an earlier study [7]. Second, there is no significant time dependence of the U(VI) speciation and coordination environment of $\mathrm{U}(\mathrm{VI})$ in these samples between 1 and 309 days equilibration time. The latter finding is in contrast with observations from TRLFS studies indicating the presence of two sorbed species [8]. Note however, that in the TRLFS study, the portion of the two species was not quantified. Third, the coordination environments of U(VI) in the hydration and diffusion samples are identical and fur- ther, agree with that of U(VI) taken-up by the crushed HCP material (sorption sample).

The latter implication is of particular importance and discloses new insights into U(VI) interaction with cementitious materials in dilute and compact systems. The three ways of sample preparation, i.e. from sorption, hydration or diffusion experiments, respectively, represent very different conditions with respect to the initial saturation state of U(VI) in solution. The preparation of the U(VI)-doped hydration and sorption samples was carried out by adding a highly concentrated U(VI) solution to non-hydrated cement or crushed HCP material, respectively. Therefore, in these samples, oversaturation with respect to a solubilitylimiting U(VI) phase might have occurred in the very early stage of sample preparation while the U(VI) loading was chosen with respect to the linear sorption isotherm [7]. This ensures that the aqueous U(VI) concentration in equilibrium with U(VI) taken up by the solid was below the solubility limit. In case of the diffusion sample, however, the U(VI) concentration on the high concentration side of the diffusion cell was controlled by a U(VI) precipitate forming under the given hyper-alkaline conditions, thus fixing the concentration at about $6 \times 10^{-6} \mathrm{M}$ [7]. Therefore, at no time, the concentration of U(VI) diffusing into the HCP disc was oversaturated with respect to the solubility-limiting $\mathrm{U}(\mathrm{VI})$ phase, implying that undersaturation or close to saturation at best was achieved. The present study clearly shows that $\mathrm{U}(\mathrm{VI})$ sorbed on cementitious material at low U(VI) loading has the same coordination environment irrespective of the experimental starting conditions, i.e. instantaneous oversaturation in the hydration and sorption samples, respectively, and undersaturation or close-to-equilibrium conditions, respectively, in the diffusion sample. Furthermore, U(VI) is preferentially accommodated by $\mathrm{C}-\mathrm{S}-\mathrm{H}$ phases in all these HCP systems, implying that U(VI) uptake by C-S-H phases accounts for the thermodynamically most stable mode of U(VI) immobilization in HCP. For example, the diffusion sample showed that the reactive zones around $\mathrm{Ca}$ and $\mathrm{Si}$-rich clinker minerals (belite), which consists of large amounts of C-S-H phases, are preferred areas of U(VI) accumulation [7].

The merged spectrum (merged_LL) was fit to determine the structural parameters of the U(VI) species formed in the HCP and C-S-H samples (Fig. 5 and Table 4).
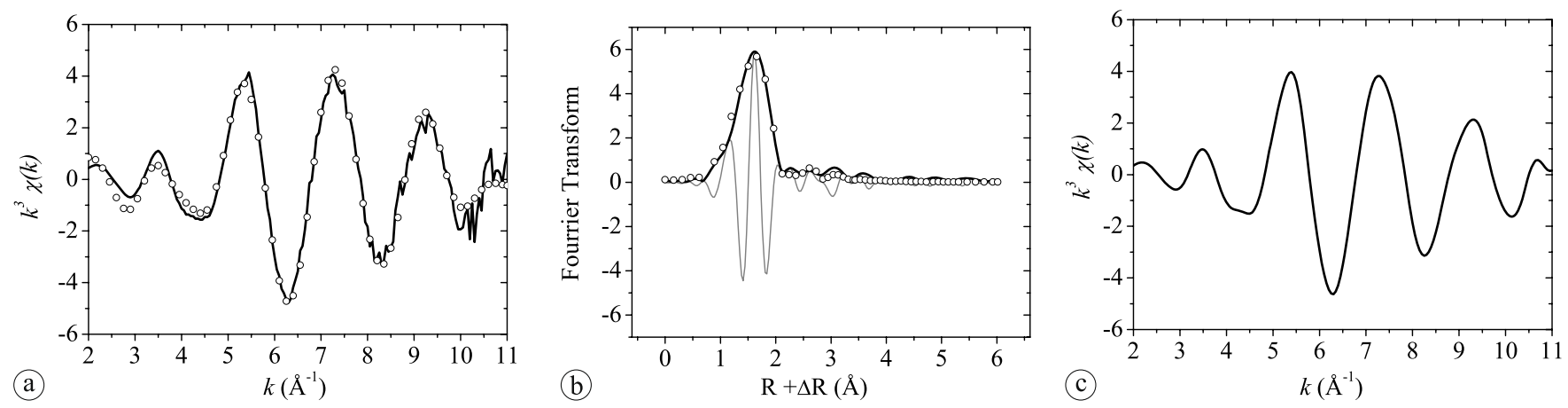

Fig. 5. Merged spectrum (merged_LL) of all spectra recorded from U(VI)-doped samples at low U(VI) loading, (a) $k^{3}$-weighted, normalized and background-subtracted EXAFS spectra, (b) experimental (solid lines) and theoretical Fourier transforms (dots: modulus; broken line: imaginary part) in the $k$ range from 2 to $11 \AA^{-1}$ (not corrected for phase shift); and (c) $k^{3}$-weighted EXAFS function of the Fourier-backtransform $(R+\Delta R$ range $=0.8-6 \AA$ ). 
Table 4. Structural parameters for the U(VI) principal component at low U(VI) loading $\left(k\right.$ range $=2-11 \AA^{-1}$ ) compared to structural parameters reported in the literature.

\begin{tabular}{|c|c|c|c|c|c|c|c|}
\hline Sample & Shell & $N$ & $\begin{array}{c}R \\
(\AA)\end{array}$ & $\begin{array}{c}\sigma^{2} \\
\left(\AA^{2}\right)\end{array}$ & $\begin{array}{l}\Delta E_{0} \\
(\mathrm{eV})\end{array}$ & $\begin{array}{c}R- \\
\text { factor }(\%)\end{array}$ & Reference \\
\hline Merged_LL & $\begin{array}{l}\mathrm{U}-\mathrm{O}_{\mathrm{ax}} \\
\mathrm{U}-\mathrm{O}_{\mathrm{eq}} \\
\mathrm{U}-\mathrm{Si}\end{array}$ & $\begin{array}{l}2.0\left(^{a}\right) \\
4.2(5) \\
0.9(3)\end{array}$ & $\begin{array}{l}1.82(2) \\
2.25(1) \\
3.10(3)\end{array}$ & $\begin{array}{l}0.004(1) \\
0.005(1) \\
0.007\left({ }^{a}\right)\end{array}$ & $10(1)$ & 0.1 & This work \\
\hline $\begin{array}{l}\mathrm{U}(\mathrm{VI}) \text {-sorbed } \\
\text { silica gel }\end{array}$ & $\begin{array}{l}\mathrm{U}-\mathrm{O}_{\mathrm{ax}} \\
\mathrm{U}-\mathrm{O}_{\mathrm{eq} 1} \\
\mathrm{U}-\mathrm{O}_{\mathrm{eq} 2}\end{array}$ & $\begin{array}{l}2\left({ }^{a}\right) \\
4(1) \\
1.6(7)\end{array}$ & $\begin{aligned} & 1.78 \\
& 2.29 \\
& 2.50(2)\end{aligned}$ & $\begin{array}{c}0.002 \\
0.014(4) \\
0.004(2)\end{array}$ & & & {$[28]$} \\
\hline $\begin{array}{l}100 \% \mathrm{UO}_{2}(\mathrm{OH})_{4}{ }^{2-} \\
\mathrm{pH}=13.7 \\
0.5 \mathrm{M} \text { TMA-OH }\end{array}$ & $\begin{array}{l}\mathrm{U}-\mathrm{O}_{\mathrm{ax}} \\
\mathrm{U}-\mathrm{O}_{\mathrm{eq}}\end{array}$ & $\begin{array}{l}1.8(3) \\
4.2(6)\end{array}$ & $\begin{array}{l}1.83 \\
2.26\end{array}$ & $\begin{array}{l}0.0010 \\
0.0046\end{array}$ & -8 & 14.0 & {$[32]$} \\
\hline $\begin{array}{l}0.055 \mathrm{M} \mathrm{UO}_{2}{ }^{2+} \\
\mathrm{pH}=14.0 \\
\text { in } 1 \mathrm{M} \text { TMA-OH }\end{array}$ & $\begin{array}{l}\mathrm{U}-\mathrm{O}_{\mathrm{ax}} \\
\mathrm{U}-\mathrm{O}_{\mathrm{eq}}\end{array}$ & $\begin{array}{l}2.0 \\
5.0(5)\end{array}$ & $\begin{array}{l}1.82 \\
2.24\end{array}$ & $\begin{array}{l}0.0015 \\
0.0056\end{array}$ & 3.7 & - & [36] \\
\hline C-S-H/1.07_30d_ads & $\begin{array}{l}\mathrm{O}_{\mathrm{ax}} \\
\mathrm{O}_{\mathrm{eq} 1} \\
\mathrm{O}_{\mathrm{eq} 2} \\
\mathrm{Si}_{1} \\
\mathrm{Si}_{2} \\
\mathrm{Ca}\end{array}$ & $\begin{array}{l}2.0\left(^{a}\right) \\
5.0(10) \\
0.5(1) \\
0.5(1) \\
2.5(5) \\
1.9(4)\end{array}$ & $\begin{array}{l}1.81(2) \\
2.26(2) \\
2.41(2) \\
3.09(2) \\
3.74(2) \\
3.81(2)\end{array}$ & $\begin{array}{c}0.003 \\
0.005 \\
0.005\left(^{a}\right) \\
0.006 \\
0.006\left(^{a}\right) \\
0.007\end{array}$ & -0.7 & 6.6 & {$[4]$} \\
\hline
\end{tabular}

a: Parameters held constant.

The resulting parameters can be compared with literature data (Table 4). The $\mathrm{U}-\mathrm{O}_{a x}$ distance of $1.82 \pm 0.02 \AA$ is similar to that in uranophane (1.82 $\pm 0.02 \AA$ [23], Table 3), $\mathrm{UO}_{2}(\mathrm{OH})_{4}{ }^{2-}(1.83 \AA[32])$ and $\mathrm{U}(\mathrm{VI})$ taken up by C-S-H phases $(1.81 \pm 0.02 \AA[4])$. The structural parameters are hence in good agreement with those reported elsewhere [7], however, with a better accuracy in the current work due to the lower signal-to-noise ratio of the merged spectrum.

The observed $\mathrm{U}-\mathrm{O}_{a x}$ distance of $1.82 \pm 0.02 \AA$ is indicative of an uranyl-silicate-like rather than a calcium-uranatelike coordination environment (to be compared with $1.79 \pm$ $0.01 \AA, 1.82 \pm 0.02 \AA$ and $1.93 \pm 0.04 \AA \mathrm{U}-\mathrm{O}_{\mathrm{ax}}$ distances of soddyite, uranophane and Ca-uranate, respectively). Using either the soddyite or the uranophane structure as fit model, no splitting of the equatorial oxygen shell could be reproduced in contrast to an earlier study [4]. Both approaches resulted in a uniform equatorial oxygen shell consisting of about four $\mathrm{O}$ atoms at average distance of $2.25 \pm 0.01 \AA$. In the soddyite structure as refined by XRD [22], two $\mathrm{O}_{\text {eq1 }}$ at $2.313 \AA$ and three $\mathrm{O}_{\text {eq2 }}$ at $2.418 \AA$ were observed. The weighted average of these distances is $2.376 \AA$. For comparison, the weighted average of $\mathrm{O}_{\mathrm{eq}}$ distances for uranophane is $2.346 \AA$. Note that a distance of $2.25 \AA$ fitted in this study is significantly shorter than the weighted average of $\mathrm{O}_{\mathrm{eq}}$ in soddyite and uranophane. It is also shorter than the averaged distance of the U(VI) surface complex (Table 4).

However, the aqueous $\mathrm{U}(\mathrm{VI})$ species $\mathrm{UO}_{2}(\mathrm{OH})_{4}{ }^{2-}$, which exists in alkaline solutions $(\mathrm{pH}=13.7)$, has two axial $\mathrm{O}$ atoms at a U- $\mathrm{O}_{\mathrm{ax}}$ distance of $1.83 \AA$ and $4.2 \pm 0.6 \mathrm{O}$ atoms at a $\mathrm{U}-\mathrm{O}_{\mathrm{eq}}$ distance of $2.26 \AA$, which is in agreement with the structural parameters obtained from the merged spectrum [32, Table 4]. At $\mathrm{pH}=14.0$, the $\mathrm{UO}_{2}(\mathrm{OH})_{4}{ }^{2-}$ species was identified as the predominant species in solution, with similar structural parameters [36, Table 4]. In hyper-alkaline solution $(\mathrm{pH}=14.5)$, Clark et al. [37] considered presence of a mixture of $\mathrm{UO}_{2}(\mathrm{OH})_{4}{ }^{2-}$ and $\mathrm{UO}_{2}(\mathrm{OH})_{5}{ }^{3-}$ in line with the structural parameters $\left(5.3 \mathrm{O}_{\mathrm{eq}}\right.$ at $\left.2.22 \AA\right)$. The coordination numbers and distances reported for the oxygen shell of the $\mathrm{UO}_{2}(\mathrm{OH})_{4}{ }^{2-}$ species are in excellent agreement with those determined for the $\mathrm{U}(\mathrm{VI})$ species taken up by cementitious materials. This finding suggests that the local arrangements of the axial and equatorial $\mathrm{O}$ atoms in the $\mathrm{U}(\mathrm{VI})$ species bound to the cementitious materials are very similar to those determined for the $\mathrm{UO}_{2}(\mathrm{OH})_{4}{ }^{2-}$ species.

Fitting of the merged spectrum further revealed that the third shell consists of about one $\mathrm{Si}$ atom at a distance of $3.10 \AA$, indicating presence of a $\mathrm{Si}$ atom at short distance as in uranyl silicate minerals. The contribution of the MS paths $\left(\mathrm{MS}_{1}, \mathrm{MS}_{2}\right.$ and $\left.\mathrm{MS}_{3}\right)$ was taken into consideration at a distance of $3.65 \AA$. Adding a second $\mathrm{Si}$ shell $\left(\mathrm{U}_{-} \mathrm{Si}_{2}\right)$ at this distance did not improve the quality of the fit. A seven-shells fit as previously proposed by Harfouche et al. [4] could not be achieved due to the relatively low signal-to-noise ratio of the EXAFS spectra and the limited $k$-range over which the spectra were collected. Therefore, no further shells beyond the third shell were considered in this study.

\subsection{Coordination environment of $\mathrm{U}(\mathrm{VI})$ in cementitious systems at high U(VI) loading}

In Fig. 6 the spectra obtained with ITT at low U(VI) loading (merged_LL) and at high U(VI) loading (HL_PC1 and HL_PC2) are compared.

The merged_LL and HL_PC1 spectra are very similar, suggesting that the $\mathrm{U}(\mathrm{VI})$ species observed at low $\mathrm{U}(\mathrm{VI})$ loading also forms at high $\mathrm{U}(\mathrm{VI})$ loading. In contrast, the HL_PC2 spectrum is different and in particular shows a pronounced feature at $4.2 \AA^{-1}$, which is characteristic for the calcium-uranate-type species (Figs. 1 and 6).

The HL_PC1 and HL_PC2 spectra were fit in the $k$ range from 2 to $10 \AA^{-1}$ to determine the structural parameters of 

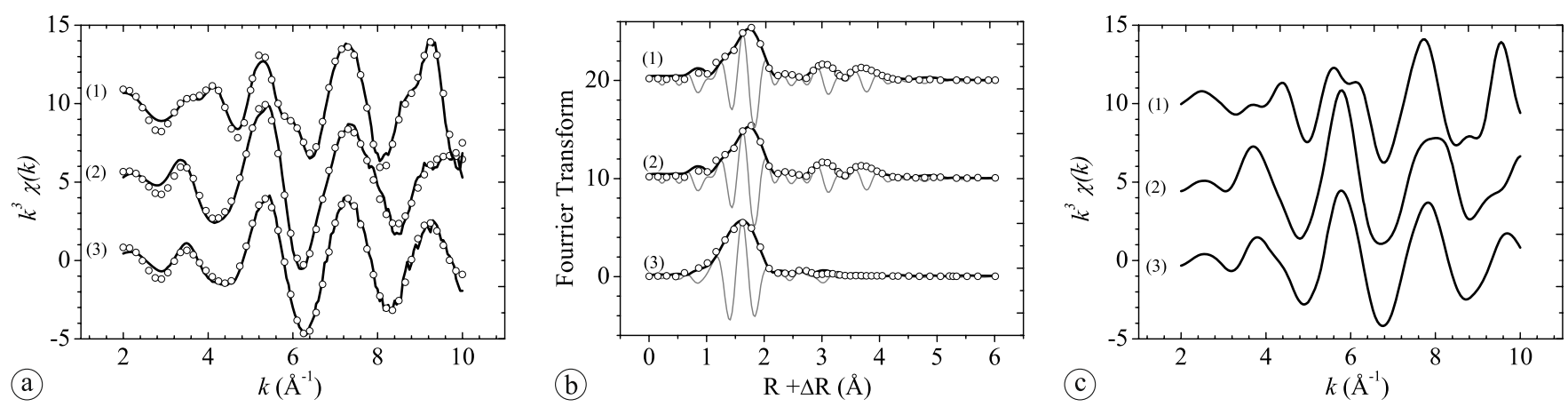

Fig. 6. Comparison of HL_PC2 (1) and HL_PC1 (2) and merged_LL (3) spectra obtained from ITT. (a) $k^{3}$-weighted, normalized and backgroundsubtracted EXAFS spectra, (b) experimental (solid lines) and theoretical Fourier transforms (dots: modulus; grey line: imaginary part) for the $k$ range from 2 to $10 \AA^{-1}$ (not corrected for phase shift); and (c) $k^{3}$-weighted EXAFS functions of the Fourier backtransform $(R+\Delta R$ range $=$ $0.8-6 \AA)$.

Table 5. Structural parameters for the two U(VI) species at high U(VI) loadings $\left(k\right.$ range $\left.=2-10 \AA^{-1}\right)$.

\begin{tabular}{llccccc}
\hline Sample & Shell & $N$ & $\begin{array}{c}R \\
(\AA)\end{array}$ & $\begin{array}{c}\sigma^{2} \\
\left(\AA^{2}\right)\end{array}$ & $\begin{array}{c}\Delta E_{0} \\
(\mathrm{eV})\end{array}$ & $\begin{array}{c}R- \\
\text { factor }(\%)\end{array}$ \\
\hline HL_PC1 & $\mathrm{O}_{\mathrm{ax}}$ & $2.0\left(^{a}\right)$ & $1.80(2)$ & $0.002(1)$ & $10(2)$ & 0.03 \\
& $\mathrm{O}_{\mathrm{eq}}$ & $5.1(8)$ & $2.28(2)$ & $0.011(2)$ & & \\
& $\mathrm{Si}$ & $1.3(8)$ & $3.13(3)$ & $0.008(6)$ & & \\
\hline \multirow{2}{*}{$\mathrm{HL}$ PC2 } & $\mathrm{O}_{\mathrm{ax}}$ & $2.0\left({ }^{a}\right)$ & $1.94(4)$ & $0.005(2)$ & $7(1)$ & 0.1 \\
& $\mathrm{O}_{\mathrm{eq}}$ & $5.0\left({ }^{a}\right)$ & $2.26(1)$ & $0.006(1)$ & & \\
& $\mathrm{Ca}$ & $4.0\left({ }^{a}\right)$ & $3.69(5)$ & $0.013(4)$ & & \\
& $\mathrm{U}$ & $3.0\left({ }^{a}\right)$ & $3.85(4)$ & $0.005(2)$ & & \\
\hline
\end{tabular}

a: Parameters held constant.

the two different species formed at high U(VI) loadings (Table 5).

The two species, HL_PC1 and HL_PC2, reveal completely different structural properties. The HL_PC1 species has structural parameters, which resemble those determined for the merged_LL spectrum. In particular, the distance of the two axial $\mathrm{O}$ atoms to the central $\mathrm{U}$ atom was determined to be $1.80 \AA .5 .1 \mathrm{O}$ atoms at a distance of $2.28 \AA$ were found in the equatorial plane and about one $\mathrm{Si}$ atom was found at a short distance of $3.13 \AA$. In contrast to the HL_PC1 species, the main structural properties of the HL_PC2 species agree with those of Ca-uranate (Table 3). The distances of the axial oxygen atoms and the five equatorial oxygen atoms were found to be $1.94 \AA$ and $2.26 \AA$, respectively. Addition of a $\mathrm{Si}$ shell did not improve the fit. However, addition of a $\mathrm{Ca}$ shell having four (held constant) $\mathrm{Ca}$ atoms and $\mathrm{a} \mathrm{U}$ shell resulted in a significant improvement of the fit and $\mathrm{Ca}-\mathrm{U}$ and $\mathrm{U}-\mathrm{U}$ distances were determined to be $3.69 \AA$ and $3.85 \AA$, respectively.

The above findings imply that even at high loading, $\mathrm{U}(\mathrm{VI})$ uptake by $\mathrm{C}-\mathrm{S}-\mathrm{H}$ phases is still a relevant immobilization process. In addition, precipitation of $\mathrm{U}(\mathrm{VI})$ in a calcium-uranate-type phase occurs, which seems to control $\mathrm{U}(\mathrm{VI})$ solubility $[3,7]$.

\subsection{Uptake mechanism of U(VI) by C-S-H phases}

More detailed considerations on the U(VI) uptake mechanism on C-S-H phases are of particular interest as we were able to corroborate the results from an earlier study [7], suggesting that $\mathrm{C}-\mathrm{S}-\mathrm{H}$ is indeed the uptake-controlling phase

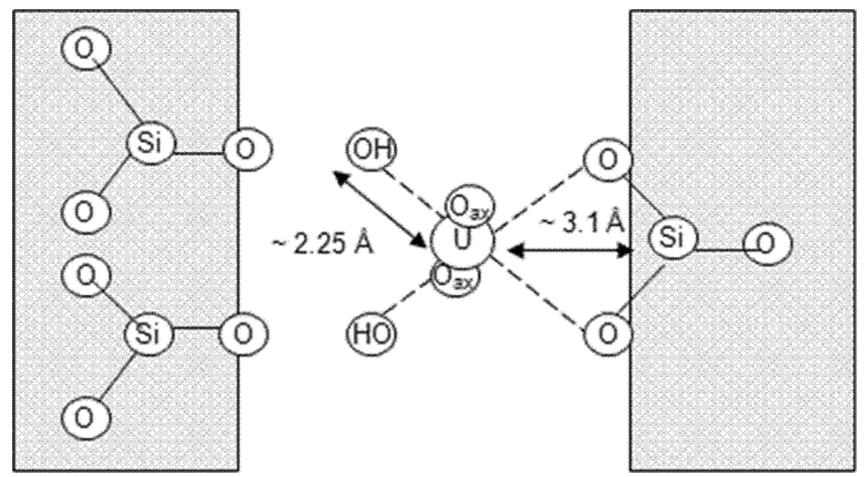

Fig. 7. Proposed structural model for the immobilization of U(VI) in the interlayer of C-S-H.

for $\mathrm{U}(\mathrm{VI})$ in HCP. Considering the structural parameters deduced from EXAFS one may envision a structural model for the $\mathrm{U}(\mathrm{VI})$ species taken up by cementitious materials at low $\mathrm{U}(\mathrm{VI})$ loading, in which a $\mathrm{UO}_{2}(\mathrm{OH})_{4}{ }^{2-}$-type species is bound to C-S-H phases.

Depending on $\mathrm{U}(\mathrm{VI})$ loading and the $\mathrm{C} / \mathrm{S}$ ratio of the solid phase, Tits et al. [8] observed two types of sorbed species in C-S-H phases by TRLFS. One of them was attributed to $\mathrm{U}(\mathrm{VI})$ being incorporated into the C-S-H structure. The spectral signature of the incorporated species was found to be shifted compared to the luminescence spectrum of the free $\mathrm{UO}_{2}(\mathrm{OH})_{4}{ }^{2-}$ species in ACW indicating a different chemical environment. According to the EXAFS data the U(VI) sorbed species are expected to be linked to one $\mathrm{Si}$ atom of the silica chain. U(VI) may either be bound to the C-S-H surface or incorporated in the interlayer of the C-S-H structure (see Fig. 7). The presently available EXAFS data do not allow an unambiguous discrimination between the two modes of interaction with cementitious materials to be undertaken.

It should be noted that the coordination environment of $\mathrm{U}(\mathrm{VI})$ taken up by cementitious materials is very different from that of U(VI) sorbed onto silica (Table 4). In particular, a split equatorial oxygen shell was observed in the latter sample while no split equatorial shell was observed for U(VI) bound to C-S-H and HCP. The proposed structural model has features of an uranyl-silicate-like structure, i.e. one $\mathrm{Si}$ atom at short distance. Nevertheless, it significantly differs from the latter structure due to absence of the split equatorial oxygen shell, such as in uranophane and soddyite. Earlier studies also suggested U(VI) incorpora- 
tion into the C-S-H structure. For example, Harfouche et al. [4] proposed a coordination environment of U(VI) taken up by C-S-H phases similar to that of U(VI) in uranophane. Wet chemistry studies on the U(VI)-C-S-H systems further suggested the formation of a solid solution (structural incorporation) [3]. Predominance of the solid solution process was anticipated due to significant re-crystallization of C-S-H phases [38]. Occurrence of the latter process implies that $\mathrm{U}(\mathrm{VI})$ could be taken up into the C-S-H structure as indicated from the earlier spectroscopic investigations $[4,8]$.

\section{Conclusions}

The results from the present study disclose new aspects in connection with the long-term safe disposal of U(VI) in a cement-based repository. The study confirms that cement materials and especially $\mathrm{C}-\mathrm{S}-\mathrm{H}$ phases play an important role in the U(VI) immobilization in the cementitious near field of a repository for radioactive waste. In particular, it is demonstrated that $\mathrm{C}-\mathrm{S}-\mathrm{H}$ is the uptake-controlling phase in the cement matrix. Furthermore, the EXAFS data suggest that $\mathrm{U}(\mathrm{VI})$ is taken up as $\mathrm{UO}_{2}(\mathrm{OH})_{4}{ }^{2-}$ type species by C-S-H phases over a wide $\mathrm{U}(\mathrm{VI})$ concentration range while the precipitation of a calcium-uranate-type phase occurs only at higher U(VI) loadings. The results from this study suggest that the same $\mathrm{U}(\mathrm{VI})-\mathrm{C}-\mathrm{S}-\mathrm{H}$ or Ca-uranate species, respectively, would form upon U(VI) interaction with hydrating cement during waste solidification and U(VI) uptake by the fully hydrated cement of the cementitious near field upon waste emplacement.

For the Swiss waste management program, as many others worldwide, it is of particular concern to demonstrate the long-term safe disposal of low- and intermediatelevel radioactive waste in a deep geological repository. The above finding, in combination with the observed long-term persistence of $\mathrm{C}-\mathrm{S}-\mathrm{H}$ phases in an evolving cementitious near field [39] implies that the cement phase controlling the uptake of U(VI) will immobilize this radionuclide over a very long period of time in the cementitious near-field of a L/ILW repository. This suggests that long-term safe disposal of $\mathrm{U}(\mathrm{VI})$ is possible.

Acknowledgment. Micro-spectroscopic studies were carried out at the Stanford Synchrotron Radiation Lightsource (SSRL), a directorate of SLAC National Accelerator Laboratory and an Office of Science User Facility operated for the U.S. Department of Energy Office of Science by Stanford University, and at the Swiss Light Source (SLS). The SSRL Structural Molecular Biology Program is supported by the DOE Office of Biological and Environmental Research, and by the National Institutes of Health, National Center for Research Resources, Biomedical Technology Program (P41PR001209). Sam Webb (BL 2-3/SSRL) is thanked for the experimental assistance during the measurements. EXAFS measurements on bulk samples were carried out at BM 20 (ROBL) at the ESRF (Grenoble, France). The staff of the ROBL/ESRF beamline is thanked for experimental assistance with the measurements. Thanks are extended to Dr. M. Marques-Fernandes and D. Kunz for assistance during the EXAFS measuring campaigns. Prof. F. P. Glasser is gratefully acknowledged for provision of the Cauranate and uranophane samples. Dr. B. Wernli and R. Brütsch are thanked for assisting in solid characterization (XRD and SEM-EDS). The study was carried out in the framework of a Marie Curie Fellowship with a grant to N.M. financed by the European Community (EC) (Contract No FP6-044811). Partial financial support was provided by the "ACTINET" project financed in the frame of the $6^{\text {th }}$ EC frame- work programme and by the National Cooperative for the Disposal of Radioactive Waste (Nagra), Switzerland.

\section{References}

1. Pointeau, I., Landesman, C., Giffaut, E., and Reiller, P.: Reproducibility of the uptake of U(VI) onto degraded cement pastes and calcium silicate hydrate phases. Radiochim. Acta 92, 645-650 (2004).

2. Wieland, E., Van Loon, L. R.: Cementitious near-field sorption database for performance assessment of an ILW repository in Opalinus Clay. Nagra Technical Report NTB 02-20, Wettingen, Switzerland (2002)

3. Tits, J., Fujita, T., Tsukamoto, M., Wieland, E.: Uranium(VI) uptake by synthetic calcium silicate hydrates. Mat. Res. Soc. Symp. Proc. 1107, 467-474 (2007).

4. Harfouche, M., Wieland, E., Dähn, R., Fujita, T., Tits, J., Kunz, D., Tsukamoto, M.: EXAFS study of U(VI) uptake by calcium silicate hydrates. J. Colloid Interf. Sci 303(1), 195-204 (2006).

5. Sylwester, E. R., Allen, P. G., Zhao, P., Viani, B. E.: Interactions of uranium and neptunium with cementitious materials studied by XAFS. Mat. Res. Soc. Symp. Proc. 608, 307-312 (2000).

6. Zhao, P., Allen, P. G., Sylwester, E. R., Viani, B. E.: The partitioning of uranium and neptunium onto hydrothermally altered concrete. Radiochim. Acta 88, 729-736 (2000).

7. Wieland, E., Macé, N., Dähn, R., Kunz, D., Tits, J.: Macro- and micro-scale studies on U(VI) immobilization in hardened cement paste. J. Radioanal. Nucl. Chem. 286, 793-800 (2010).

8. Tits, J., Geipel, G., Macé, N., Eilzer, M., Wieland, E.: Determin-

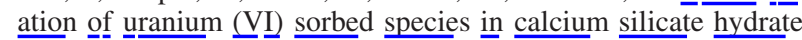
phases: a laser-induced luminescence spectroscopy and batch sorption study. J. Colloid Interf. Sci. 359, 248-256 (2011).

9. Moroni, L. P., Glasser, F. P.: Reaction between cement components and U(VI) oxide. Waste Manage. 15(3), 243-254 (1995).

10. Skakle, J. M., Moroni, L. P., Glasser, F. P.: $\underline{X}-$ ray diffraction data for two new calcium uranium(VI) hydrates. Powder Diffr. 12, $\overline{81}$ $\overline{86}(199 \overline{7})$.

11. Moll, H., Matz, W., Schuster, G., Brendler, E., Bernhard, G., Nitsche, H.: Synthesis and characterisation of uranyl orthosilicate $\left(\mathrm{UO}_{2}\right)_{2} \mathrm{SiO}_{4} \cdot 2 \mathrm{H}_{2} \mathrm{O}$. J. Nucl. Mater. 227, 40-49 (1995).

12. Wieland, E., Tits, J., Ulrich, A., Bradbury, M. H.: Experimental evidence for solubility limitation of the aqueous $\mathrm{Ni}$ (II) concentration and isotopic exchange of ${ }^{63} \mathrm{Ni}$ in cementitious systems. Radiochim. Acta 94, 29-36 (2006).

13. Tits, J., Wieland, E., Müller, C. J., Landesman, C., Bradbury, M. H.: Strontium binding by calcium silicate hydrates. J. Colloid Interf. Sci. 300, 78-87 (2006).

14. Vespa, M., Dähn, R., Grolimund, D., Wieland, E., Scheidegger, A. M.: Spectroscopic investigation of Ni speciation in hardened cement paste. Environ. Sci. Technol. 40, 2275-2282 (2006).

15. $\overline{M a t z}, \bar{W} .$, Schell, N., Bernhard, G., Prokert, F., Reich, T., Claußner, J., Oehme, W., Schlenk, R., Dienel, S., Funke, H., Eichhorn, F., Betzl, M., Prohl, D., Strauch, U., Huttig, G., Krug, H., Neumann, W., Brendler, V., Reichel, P., Denecke, M., Nitsche, H.: ROBL - a CRG beamline for radiochemistry and materials research at the ESRF. J. Synchrotron Radiat. 6, 1076-1085 (1999).

16. Manceau, A., Marcus, M. A., Tamura, N.: Quantitative speciation of heavy metals in soils and sediments by synchrotron Xray techniques. In: Application of Synchrotron Radiation in LowTemperature Geochemistry and Environmental Science. (Fenter, P. A., Rivers, M. L., Sturchio, N. C., Sutton, S. R., eds). Mineralogical Society of America, Washington DC (2002), vol. 49, p. 341.

17. Marcus, M. A., MacDowell, A. A., Celestre, R., Manceau, A., Miller, T., Padmore, H. A., Sublett, R. E.: Beamline 10.3.2 at ALS: a hard X-ray microprobe for environmental and materials sciences. J. Synchrotron Radiat. 11, 239-247 (2004).

18. Webb, S. M.: SIXXack a graphical user interface for EXXE alysis using IFEFFIT. Phys. Scripta 115, 1011-1014 (2005).

19. $\overline{\text { Ravel}}, \bar{B}$., Newville, M.: ATHENA, ARTEMIS, HEPHAESTUS: data analysis for X-ray absorption spectroscopy using IFEFFIT. J. Synchrotron Radiat. 12, 537-541 (2005).

20. Newville, M.: EXAFS analysis using FEFF and FEFFIT. J. Synchrotron Radiat. 8, 96-100 (2001). 
21. Rehr, J. J., Mustre De Leon, J., Zabinsky, S. I., Albers, R. C.: Theoretical X-ray absorption fine structure standards. J. Amer. Chem. Soc. 113, 5135-5140 (1991).

22. Rehr, J. J.: Theoretical approaches to X-ray absorption fine structure. Rev. Mod. Phys. 72, 621-654 (2000).

23. Ginderow, D.: Structure de l'uranophane alpha, $\mathrm{Ca}\left(\mathrm{UO}_{2}\right)_{2}$ $\left(\mathrm{SiO}_{3} \mathrm{OH}\right)_{2} \cdot 5 \mathrm{H}_{2} \mathrm{O}$. Acta Crystallogr. C 44, 421-424 (1988).

24. Demartin, F., Gramaccioli, C. M., Pilati, T.: The importance of accurate crystal structure determination of uranium minerals. II. Soddyite $\left(\mathrm{UO}_{2}\right)_{2}\left(\mathrm{SiO}_{4}\right) \cdot 2 \mathrm{H}_{2} \mathrm{O}$. Acta Crystallogr. C 48, 1-4 (1992).

25. Hudson, E. A., Allen, P. G., Terminello, L. J., Denecke, M. A., Reich, T.: Polarized X-ray absorption spectroscopy of the uranyl ion: Comparison of experiment and theory. Phys. Rev. B 54, $\overline{156}-\overline{1} \overline{65}(\overline{1996)}$.

26. Stern, E. A., Heald, S. M.: Basic principles and applications of EXAFS. In: Handbook of Synchrotron Radiation. (Koch, E. E., ed.) North-Holland, Amsterdam (1983), p. 995.

27. Takahashi, K., Fujino, T., Morss, L. R.: Crystal chemical and thermodynamic study on $\mathrm{CaUO}_{4-x},\left(\mathrm{Ca}_{0.5} \mathrm{Sr}_{0.5}\right) \mathrm{UO}_{4-x}$, and alpha$\mathrm{SrUO}_{4-x}(x=0-0.5)$. J. Solid State Chem. 105, 234-246 (1993).

28. Burns, P. C., Li, Y.: The structures of becquerelite and $\mathrm{Sr}$ exchanged becquerelite. Amer. Mineral. 87, 550-557 (2002).

29. Burns, P. C.: The structure of boltwoodite and implications of solid solution toward sodium boltwoodite. Can. Mineral. 36, 1069-1075 (1998).

30. Reich, T., Moll, H., Denecke, M. A., Geipel, G., Bernhard, G., Nitsche, H., Allen, P. G., Bucher, J. J., Kaltsoyannis, N., Edelstein, N., Shuh, D. K.: Characterisation of hydrous uranyl silicate by EXAFS. Radiochim. Acta 74, 219-223 (1996).
31. Thompson, H. A., Brown, G. E., Parks, G. A.: XAFS spectroscopic study of uranyl coordination in solids and aqueous solution. Amer. Mineral. 82, 483-496 (1997).

32. Moll, H., Reich, T., Szabo, Z.: The hydrolysis of dioxouranium (VI) investigated using EXAFS and ${ }^{17} \mathrm{O}-\mathrm{NMR}$. Radiochim. Acta 88, 411-415 (2000).

33. Catalano, J. G., Brown, G. E.: Analysis of uranyl-bearing phases by EXAFS spectroscopy: Interferences, multiple scattering, accuracy of structural parameters and spectral differences. Amer. Mineral. 89, 1004-1021 (2000).

34. Burns, P. C., Miller, M. L., Ewing, R. C.: $\mathrm{U}^{6+}$ minerals and inorganic phases: a comparison and hierarchy of crystal structure. Can. Mineral. 34, 845-880 (1996).

35. Allard, T., Ildefonse, P., Beaucaire, C., Calas, G.: Structural chemistry of uranium associated with $\mathrm{Si}, \mathrm{Al}, \mathrm{Fe}$ gels in a granitic uranium mine. Chem. Geol. 158, 81-103 (1999).

36. Wahlgren, H., Moll, H., Grenthe, I., Schimmelpfennig, B., Maron, L., Vallet, V., Gropen, O.: Structure of uranium(VI) in strong alkaline solution. A combined theoretical and experimental investigation. J. Phys. Chem. A 103, 8257-8264 (1999).

37. Clark, D. L., Conradson, S. D., Donohoe, R. J., Keogh, D. W., Morris, D. E., Palmer, P. D., Rogers, R. D., Tait, C. D.: Chemical speciation of the uranyl ion under highly alkaline conditions. Synthesis, structures, and oxo ligand exchange dynamics. Inorg. Chem. 38, 1456-1466 (1999).

38. Mandaliev, P., Dähn, R., Wehrli, B., Wieland, E.: Macro- and microspectroscopic study of $\mathrm{Nd}(\mathrm{III})$ uptake mechanisms in hardened cement paste. Environ. Sci. Technol. 43, 8462-8468 (2009).

39. Glasser, F. P.: Characterisation of the barrier performance of cements. Mat. Res. Soc. Symp. Proc. 713, 721-732 (2002). 